\title{
Polyurethanes from the crystalline prepolymers resistant to abrasive wear
}

\author{
Agata Domańska $^{1 *}$, Anna Boczkowska ${ }^{*}$, Marta Izydorzak-Woźniak ${ }^{1}$, Zbigniew Jaegermann², \\ Małgorzata Grądzka-Dahlke \\ ${ }^{1}$ Warsaw University of Technology, Faculty of Materials Science and Engineering, Woloska 141, 02-507 Warsaw, Poland \\ ${ }^{2}$ Institute of Ceramics and Building Materials, Postepu 9, 02-676 Warsaw, Poland \\ ${ }^{3}$ Bialystok University of Technology, Faculty of Mechanical Engineering, Wiejska 45C, 15-351 Biatystok, Poland \\ * Corresponding authors: e-mail: agata.domanska@inmat.pw.edu.pl, anna.boczkowska@inmat.pw.edu.pl
}

\begin{abstract}
The research aimed at the selection of polyurethanes synthesized from poly(tetramethylene ether) glycol (PTMEG), as well as from two different isocyanates 4,4'-methylenebis(cyclohexyl)isocyanate (HMDI) and 4.4'-methylenebis(phenyl isocyanate) (MDI) in order to obtain polyurethane with increased resistance to abrasive wear and degradation for bio-medical application. Polyurethanes were fabricated from crystalline prepolymers extended by water. The paper presents preliminary results on polyurethane surface wettability, friction coefficient for different couples of the co-working materials such as polyurethane-polyurethane, polyurethane-titanium alloy, polyurethane-alumina, in comparison to commonly used polyethylene-titanium alloy. Shear strength of polyurethane-alumina joint, as well as viscosity of prepolymers were also measured. The values of friction coefficient were compared to literature data on commercially available polyurethane with the trade name Pellethane. Polyurethanes obtained are characterized by low abrasive wear and low friction coefficient in couple with the titanium alloy, what makes them attractive as possible components of ceramic-polymer endoprosthesis joints.
\end{abstract}

Keywords: polyurethane, crystalline prepolymer, abrasive wear, adhesion, friction coefficient, endoprosthesis.

\section{INTRODUCTION}

Polymeric biomaterials, due to their properties, are quickly replacing materials such as metal alloys and ceramics, commonly used in medical applications. In 2003 , sales of polymeric biomaterials exceeded $\$ 7$ billion, accounting for almost $88 \%$ of the total biomaterials market for that year ${ }^{1}$.

Polymeric materials used in medicine can be divided into several groups depending on their types and the time of contact with the patient's tissue. There are materials used externally, having direct or indirect contact with tissues or blood, materials used as implants in contact with both tissues and blood, materials in contact with mucosa and the damaged outer tissue and the ones without contact with tissues ${ }^{2}$. Materials used in contact with tissue can be divided into biodegradable or resistant to degradation. Biodegradable polymers are used, inter alia, as scaffolds for tissues engineering ${ }^{3}$, and the resistant to degradation ones, for example, as implants of the intervertebral discs ${ }^{4}$.

This paper describes polyurethane resistant to abrasive wear and degradation, developed for application as the material working in the so-called friction node of ceramicpolymer endoprosthesis joints (Fig. 1) ${ }^{5}$. The idea of that endoprosthesis was arisen in the Institute of Ceramics and Building Materials in Warsaw and described in ${ }^{5,6,7}$. It was assumed that polyurethanes for this application should posses good adhesion to the ceramic core and low friction coefficient when working in a friction node with ceramic or metallic layers.

Polyurethane resistant to abrasive wear and degradation was synthesized from the crystalline prepolymers extended by water at the Faculty of Materials Science and Engineering, Warsaw University of Technology ${ }^{8}$. Within this method, water is used as a chain extender of - NCO prepolymer reactive groups. Prepolymers are usually used in reaction in the form of liquid. However, in case of their reaction with water a by-product in

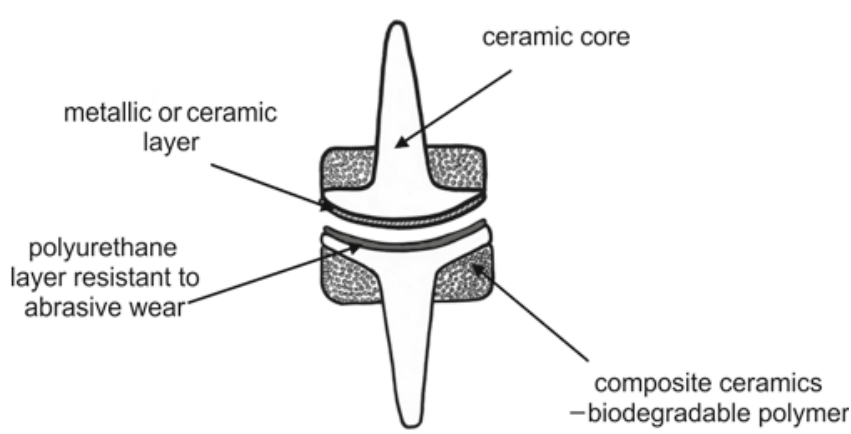

Figure 1. Scheme of the ceramic-polymer endoprosthesis ${ }^{5}$

the form of carbon dioxide is formed. The method in which the reaction is carried out with the use of solid crystalline prepolymer was developed at Warsaw University of Technology, Faculty of Materials Science and Engineering. That prevents formation of discontinuities in the polymeric material in the form of pores created by carbon dioxide. Polyurethane made from crystalline prepolymers extended by water was characterized and particularly described in earlier studies, ${ }^{\mathbf{9}}$.

\section{MATERIAL AND METHODS}

Polyurethanes were synthesized from the following substrates:

- oligodiol: poly(tetramethylene ether) glycol (PTMEG) with the average molecular weight of $2000 \mathrm{~g} / \mathrm{mol}$, supplied by Du Pont,

- isocyanates:

a) 4,4'-methylenebis(cyclohexyl)isocyanate (HMDI), supplied by Sigma-Aldrich,

b) 4,4`-methylenebis(phenyl isocyanate) (MDI), supplied by Sigma-Aldrich,

c) distilled water (w) as chain extender.

Polyurethanes were obtained by the prepolymer method. The molar ratio of isocyanate to oligodiol was 2:1 in each case. Elongation of prepolymer chains was 
carried out using polycondensation reaction with water. As a result of the polycondensation reaction of isocyanate groups with water a $\mathrm{CO}_{2}$ by-product is formed. Therefore, as previously stated, in order to limit the formation of bubbles of $\mathrm{CO}_{2}$ in the polyurethane bulk, reaction of polycondensation was carried out with application of prepolymer solidified by its crystallization. Crystallization of the prepolymer was carried out at $7^{\circ} \mathrm{C}$. The temperature of $7^{\circ} \mathrm{C}$ was selected on the basis of our previous studies ${ }^{5}$. Infrared spectroscopy studies (FTIR) confirmed that prepolymer was completely reacted with water because no residual - NCO groups were found in the synthesized samples ${ }^{5}$. Samples of fabricated polyurethanes and their codes are listed in the Table 1.

Table 1. Synthesized samples of polyurethanes

\begin{tabular}{|l|c|c|}
\hline $\begin{array}{l}\text { Type of } \\
\text { polyurethane }\end{array}$ & Type of oligodiol & Type of isocyanate \\
\hline PTMEG/MDI & $\begin{array}{c}\text { poly(tetramethylene } \\
\text { ether) glycol } \\
\text { (PTMEG) }\end{array}$ & $\begin{array}{c}4,4^{2} \text {-methylenebis(phenyl } \\
\text { isocyanate) (MDI) }\end{array}$ \\
\hline PTMEG/HMDI & $\begin{array}{c}\text { poly(tetramethylene } \\
\text { ether) glycol } \\
\text { (PTMEG) }\end{array}$ & $\begin{array}{c}4,4^{\prime} \text {-methylenebis } \\
\text { (cyclohexyl)i socyanate } \\
\text { (HMDI) }\end{array}$ \\
\hline
\end{tabular}

In order to study adhesion of polyurethanes to ceramics, alumina plates with varying surface roughness were prepared. Varying roughness of alumina surfaces was achieved by introducing an organic filler to alumina powder, removed after sintering, leaving pores on the surface of the material. As a basic component of alumina material the alumina powder Nabalox ${ }^{\circledR}$ 713-10 (Nabaltec), $\mathrm{Al}_{2} \mathrm{O}_{3}$ content min. 99\% was used and 5, 15 or $30 \mathrm{wt} \%$ of cornstarch was applied as a filler. Samples were coded respectively: "Al5S", "Al15S" and "Al30S". The alumina plates without cornstarch were also prepared (coded "Al"). The same material was used to prepare ground and polished alumina discs (coded " $\mathrm{Al}_{2} \mathrm{O}_{3}$ ") with a diameter of $25 \mathrm{~mm}$ and a height of $3 \mathrm{~mm}$, manufactured in order to perform the friction tests. Laser profilometer Veeco, Wyko NT9300 was used in order to illustrate the surface topography of alumina samples. For the sake of evaluation of the degree of samples roughness, $R_{a}$ and $\mathrm{R}_{\mathrm{z}}$ parameters were determined using a mechanical surface analyzer.

Wettability of tested polyurethanes was evaluated by measuring the contact angle at room temperature by the sessile drop method using PGX goniometer (Fibro Systems AB). Abrasive wear was measured according to Schopper-Schlobbach method (PN-ISO 4649:2007 standard). Hardness measurements were performed using Shore method in accordance with PN-EN ISO 868. Samples with dimensions of 30x50x6 mm were tested. The results are expressed as the arithmetic mean of several measurements for each sample.

Young's modulus E tests were performed using $2 \times 5 \times 70 \mathrm{~mm}$ samples under tension rate of $500 \mathrm{~mm} / \mathrm{min}$. During the measurement the clamping jaws of INSTRON machine type 1115 were clenched on the measuring basis of $1_{0}=20 \mathrm{~mm}$. The Young's modulus was determined from the initial linear section of the force-elongation curve, according to the formula:

$E=\frac{P_{E} \cdot l_{0}}{A_{0} \cdot \Delta l}[\mathrm{MPa}]$ where:

$\mathrm{P}_{\mathrm{E}}$ - force determined to the initial linear section of the force-elongation curve [N],

$\mathrm{Dl}$ - elongation corresponding to $\mathrm{P}_{\mathrm{E}}$ force [mm],

$\mathrm{A}_{0}-$ cross section area of the sample $\left[\mathrm{mm}^{2}\right]$.

All tests were carried out for five samples of each material and the results are given as arithmetic mean of the results obtained.

Examination of tear strength was performed according to the standard PN-ISO 34-1 using standard notched specimens and the machine INSTRON type 1115. Tear strength was calculated from the formula:

$R_{r d}=\frac{P_{r d}}{g}[\mathrm{kN} / \mathrm{m}]$

where:

$\mathrm{P}_{\mathrm{rd}}$ - breaking force of the sample $[\mathrm{kN}]$,

$\mathrm{g}$ - sample thickness [m].

Tests were carried out for five samples of each material and the results are given as arithmetic mean of the results obtained.

Tribological tests were performed with a simulator of friction in hip joints, designed at the Faculty of Mechanical Engineering of Bialystok University of Technology. The study was carried out using couples of materials in the form of ring and disc in $0,1 \%$ aqueous solution of sodium chloride $(\mathrm{NaCl})$ as lubricating agent. Friction coefficient was calculated from the formula $\mu=\mathrm{T} / \mathrm{N}$, where $\mathrm{T}$ is friction force and $\mathrm{N}$ is pressure.

Adhesion of polyurethanes to alumina ceramics was evaluated based on the shear strength. The shear forces were measured using the Lloyd LR 10K testing machine and calculated with the Nexygen 3.0 program. Samples composed of two alumina plates with the size of $5 \times 7 \times 37 \mathrm{~mm}$ connected to a layer of polyurethane (Fig. 2). Alumina plates were prepared in the Institute of Ceramics and Building Materials in Warsaw.

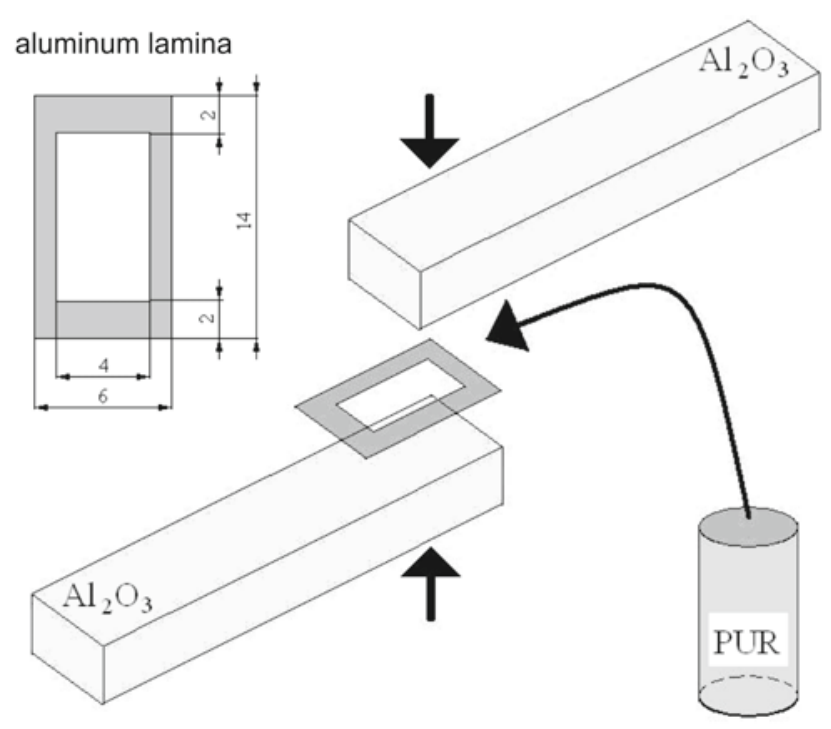

Figure 2. Schematic explanation of the sample preparation for shear strength measurements ${ }^{11}$

Viscosity of prepolymers before crystallization, from which polyurethanes were produced, was examined as a function of time at $100^{\circ} \mathrm{C}$ with the viscometer type Brookfield model DV-II+Pro. Liquid prepolymer was stirred at a constant shear rate equal to $1 \mathrm{~s}^{-1}$. Due to 
technical reasons every $5 \mathrm{~s}$ before each measurement the shear rate was increased to $4.65 \mathrm{~s}^{-1}$.

Microstructure of polyurethanes, alumina ceramics and joints was observed using scanning electron microscope (SEM) TM 3000 Hitachi.

\section{RESULTS AND DISCUSSION}

Preliminary results of the obtained materials indicated that polyurethanes made from crystalline prepolymers extended by water were characterized by interesting properties with the perspective of application as components of ceramic-polymer endoprotesthesis joints ${ }^{5}$. It was also reported ${ }^{5}$, that polyurethanes from crystalline prepolymers extended by water, based on polytetramethylene ether glycol, are characterized by higher wear resistance and lower density as compared to PU obtain from poly(ethylene adipate) (PEA). Therefore, in this work the studies are focused on PTMEG-based polyurethanes (PU). Properties of PU samples fabricated in this study compared to literature data of Pellethane 2363-80A were shown in the Table 2.

Existing literature acknowledges ${ }^{\mathbf{1 2}}$ that when aromatic isocyanate is used for polyurethane fabrication, the material is characterized by improved mechanical properties. The same rule was confirmed by the results obtained in this study for the polyurethanes synthesized in the reaction of crystalline prepolymer with water. Polyurethane based on MDI (PTMEG/MDI sample) is characterized by higher hardness $\mathrm{H}$, Young's modulus $\mathrm{E}$ and tear strength $\mathrm{R}_{\mathrm{rd}}$ than polyurethane obtained from HMDI (PTMEG/HMDI sample). Fabricated polyurethanes are characterized by much lower density r, higher hardness $\mathrm{H}$ and Young's modulus $\mathrm{E}$ than commercially available Pellethane 2363-80A.

Wetting of the polyurethane surface was evaluated by measuring the static contact angle with water. The contact angle above $90^{\circ}$ characterizes hydrophobic surfaces, while hydrophilic ones with good wettability are characterized by a contact angle of less than $90^{\circ 19}$. Hydrophobic materials are more resistant to degradation.

The results of contact angle measurement (Table 3) show that polyurethanes based on poly(tetramethylene ether) glycol (PTMEG) are hydrophobic (contact angle above $90^{\circ}$ ). This confirms the theory that the polyurethanes prepared from polyether (e.g. PTMEG) are less susceptible to hydrolysis, which leads to degradation of the material ${ }^{\mathbf{1 2}, \mathbf{2 0}}$. The contact angle value does not depend on the kind of isocyanate used. In the case of polyurethanes obtained from PTMEG, contact angle remains at the level of $90-92^{\circ}$, independently of the isocyanates type (MDI or HMDI).
Literature data report that commercial polyurethane with the trade name Pellethane from Dow Chemical, based on poly(tetramethylene ether) glycol (PTMEG), 4.4 '-methylenebis(phenyl isocyanate) (MDI) and 1.4-butanediol is characterized by a low tribological wear and contact angle in the range from $92^{\circ 17}$ to $99^{\circ 18}$. Polyurethanes produced in this study based on poly(tetramethylene ether) glycol (PTMEG) exhibit comparable tribological wear and contact angle to the commercially available Pellethane.

In order to evaluate wear properties of the produced polyurethanes, friction coefficient for different couples of materials, such as polyurethane-polyurethane, polyurethane-titanium alloy (Ti6Al4V), polyurethane-alumina ceramics $\left(\mathrm{Al}_{2} \mathrm{O}_{3}\right)$, in comparison to commonly used polyethylene (UHMWPE)-titanium alloy (Ti6Al4V) was tested. The values of friction coefficient are shown in Figure 3.

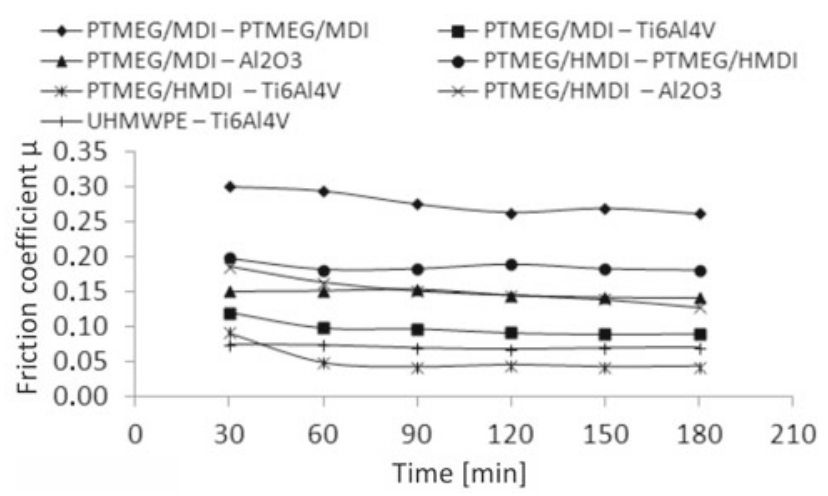

Figure 3. Friction coefficient as a function of time for the tested couples of materials

The study has shown that the highest friction coefficient is obtained within polyurethane-polyurethane couple. It is acknowledged in the existing literature that friction coefficient for the couple composed of the same polymeric materials is higher than in the case of couples composed of two different materials, e.g. polymer-metal or polymer-ceramics ${ }^{\mathbf{2 1}}$. Values of the friction coefficient for polyurethane-alumina couple obtained were lower than for polyurethane-polyurethane ones. However, there was no effect of the kind of polyurethane in a polyurethane-alumina couple, as both curves almost overlapped. Examples of polyurethane surface after the friction tests in contact with alumina ceramics are presented in Figure 4. It can be observed that after friction in contact with alumina surface, polyurethane was pulled-out at the boundary of spherulites formed during crystallization of the prepolymer. It confirms our previously described observations ${ }^{\mathbf{9}} \mathbf{1 0}$ that the PU hard segments (less resistant to abrasive wear than soft segments) are formed mainly on the spherulites surface

Table 2. Comparison of density $(\rho)$, abrasive wear $(\Delta V)^{\mathbf{5}}$, contact angle $(\varphi)$, hardness $(H)$, Young's modulus (E), tear strength $\left(\mathrm{R}_{\mathrm{rd}}\right)$ of tested polyurethanes to commercially available Pellethane $2363-80 \mathrm{~A} 13^{14,15}, 16,17,18$

\begin{tabular}{|l|l|l|c|c|c|c|}
\hline Type of polyurethane & $\rho\left[\mathrm{g} / \mathrm{cm}^{3}\right]$ & $\Delta \mathrm{V}\left[\mathrm{cm}^{3}\right]$ & $\varphi\left[^{\circ}\right]$ & $\mathrm{H}\left[^{\circ} \mathrm{Sh}\right]$ & $\mathrm{E}[\mathrm{MPa}]$ & $\mathrm{R}$ rd $[\mathrm{kN} / \mathrm{m}]$ \\
\hline PTMEG/MDI & $\begin{array}{l}1.0833 \pm \\
0.0035\end{array}$ & $\begin{array}{l}0.0238 \pm \\
0.0024\end{array}$ & $91.5 \pm 0,5$ & $48 \pm 0.7^{\circ} \mathrm{Sh} \mathrm{D}$ & $12.8 \pm 1.6$ & $100 \pm 13.5$ \\
\hline PTMEG/HMDI & $\begin{array}{l}1.0556 \pm \\
0.0030\end{array}$ & $\begin{array}{l}0.0264 \pm \\
0.0002\end{array}$ & $90.0 \pm 0,5$ & $45 \pm 1.0^{\circ} \mathrm{Sh} \mathrm{D}$ & $11.8 \pm 1.0$ & $92 \pm 1.3$ \\
\hline $\begin{array}{l}\text { Pellethane } \\
2363-80 \mathrm{~A}\end{array}$ & $1.1300^{*}$ & - & $92-99^{*}$ & $80-83^{\circ} \mathrm{Sh} \mathrm{A}^{*}$ & $8^{*}$ & - \\
\hline
\end{tabular}

*data taken from the literature $[13,14,15,16,17,18]$. 

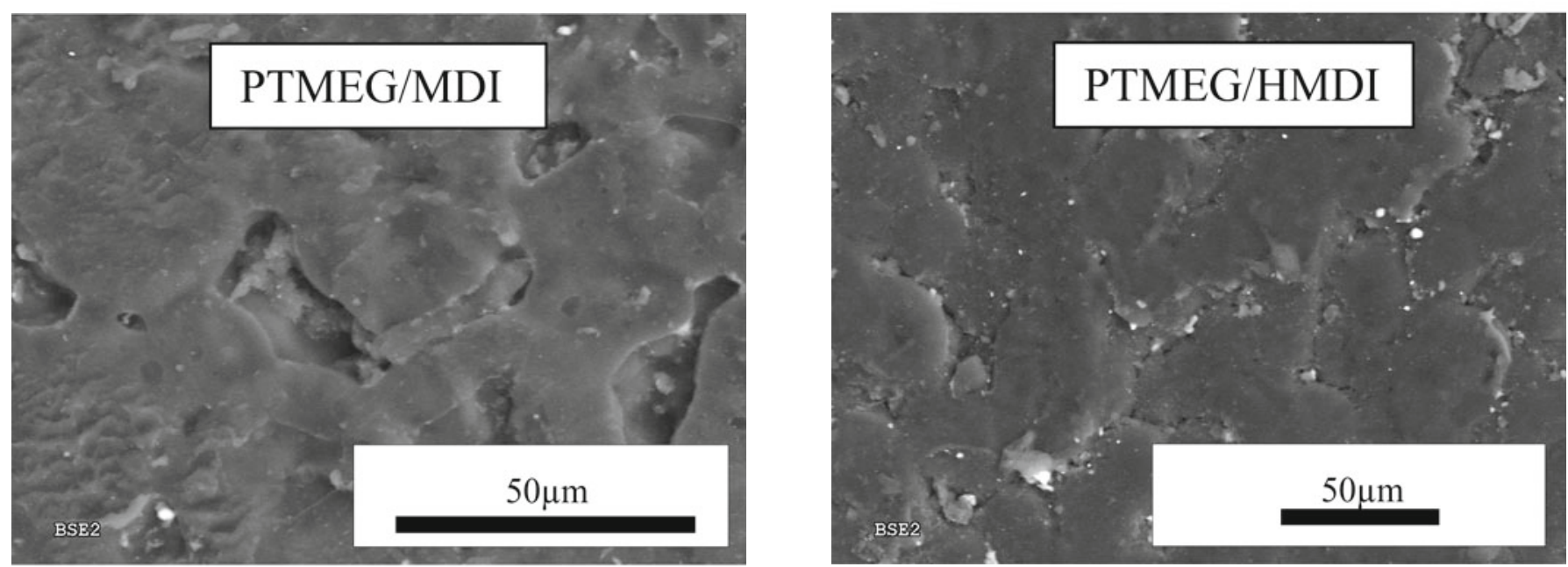

Figure 4. SEM images of polyurethane surfaces after the friction tests for polyurethane - ceramic couples

as the result of reaction of prepolymer -NCO groups located at the spherulites surface with water.

The lowest friction coefficient was obtained in the case of PTMEG/HMDI-Ti6Al4V couple. The results have shown that polyurethanes obtained from poly(tetramethylene ether) glycol (PTMEG) and 4,4'-methylenebis(cyclohexyl)isocyanate (HMDI) extended by water tested in the contact with titanium alloy are characterized by lower friction coefficient than couple of ultra high molecular weight polyethylene with titanium alloy commonly used as friction elements in endoprosthesis joint.

Studies carried out by Schwarz and Bahadur ${ }^{22}$ present wear data for Pellethane 2363-80A and UHMWPE in contact with 316LS surgical stainless steel. These results proved that mean wear of Pellethane $2363-80 \mathrm{~A}$ is
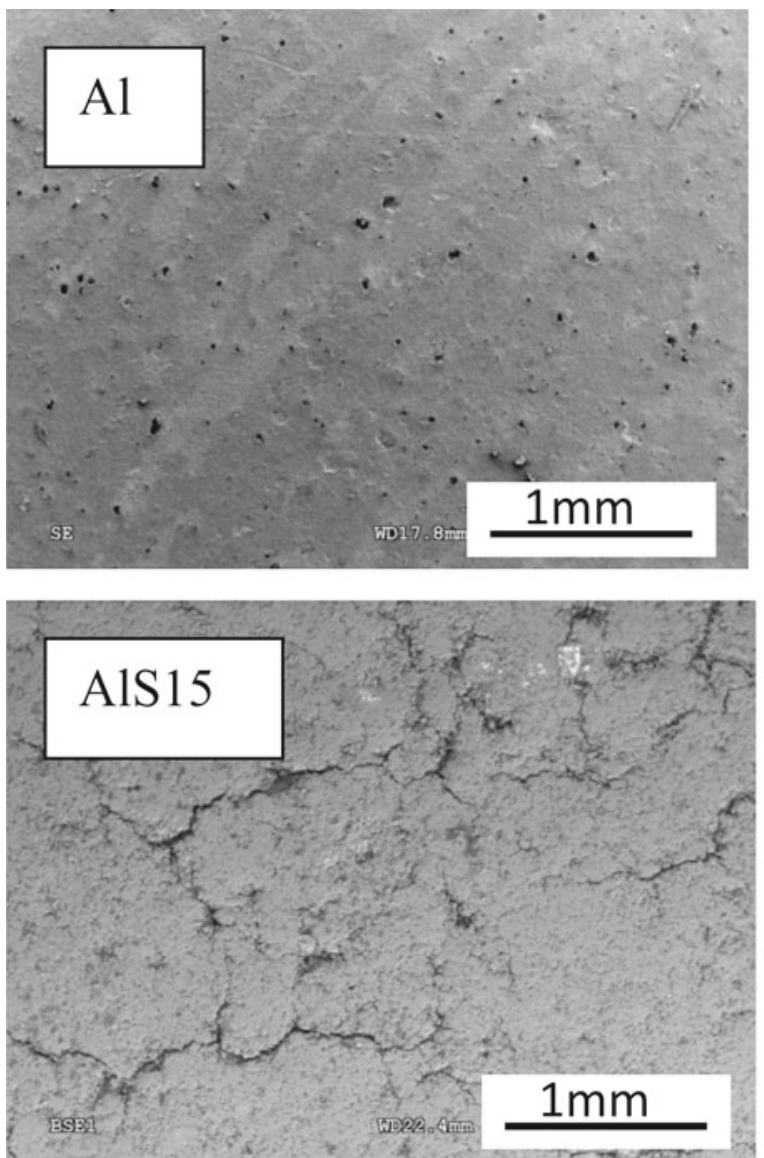

lower than the ultra high molecular weight polyethylene (Table 3).

Table 3. Comparison of mean wear of the ultra high molecular weight polyethylene and Pellethane 2363-80A in contact with $316 \mathrm{LS}$ surgical stainless stee ${ }^{22}$

\begin{tabular}{|l|c|}
\hline Material & Mean wear $\left[\mathrm{mm}^{3}\right]$ \\
\hline UHMWPE & 0.408 \\
\hline Pellethane 2363-80A & 0.200 \\
\hline
\end{tabular}

It can be supposed that PUs based on poly(tetramethylene ether) glycol (PTMEG) exhibit lower mean wear than the UHMWPE currently used as friction element in endoprosthesis joint. When comparing the results of UHMWPE with Ti6Al4V friction to PTMEG/HMDI with Ti6Al4V it can be noticed that friction coefficient is also lower for the second couple (Fig. 3).
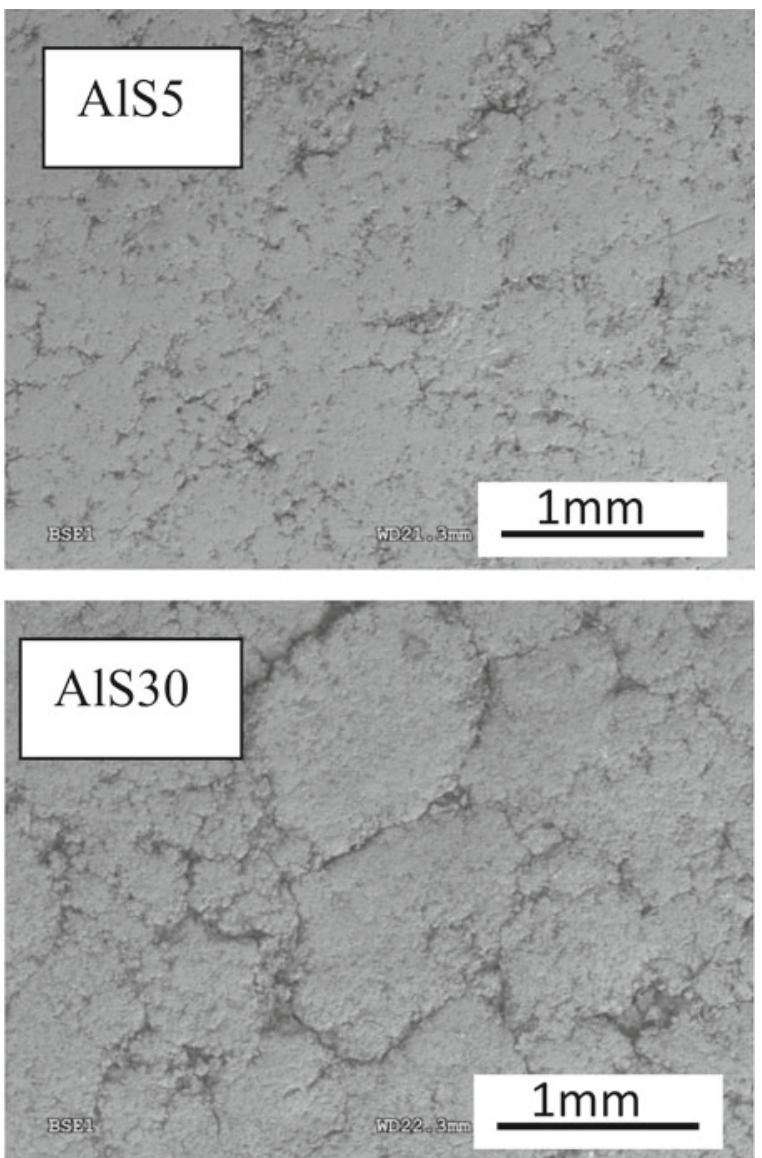

Figure 5. The microstructure of the surface of alumina plates (SEM images) 
Shear strength tests of the alumina-polyurethane joints were conducted in order to evaluate adhesion of polyurethane to the alumina ceramics. For this study four sets of alumina plates with varying surface roughness were used (Table 4). SEM and laser examination allowed to determine the degree of alumina surface topography. The highest roughness of the surface area was obtained for the sample AlS30 and the lowest for the sample Al. Images of microstructure and topography of alumina surfaces are shown in Figures 5 and 6.

Table 4. Roughness parameters $\left(R_{a}, R_{z}\right)$ for alumina plates (mechanical surface analyzer)

\begin{tabular}{|l|c|r|}
\hline Code of alumina plate & $\mathrm{R}_{\mathrm{a}}[\mu \mathrm{m}]$ & $\mathrm{R}_{\mathrm{z}}[\mu \mathrm{m}]$ \\
\hline $\mathrm{Al}$ & 0.696 & 5.760 \\
\hline AIS5 & 1.155 & 10.909 \\
\hline AIS15 & 1.904 & 15.547 \\
\hline AIS30 & 4.657 & 30.522 \\
\hline
\end{tabular}

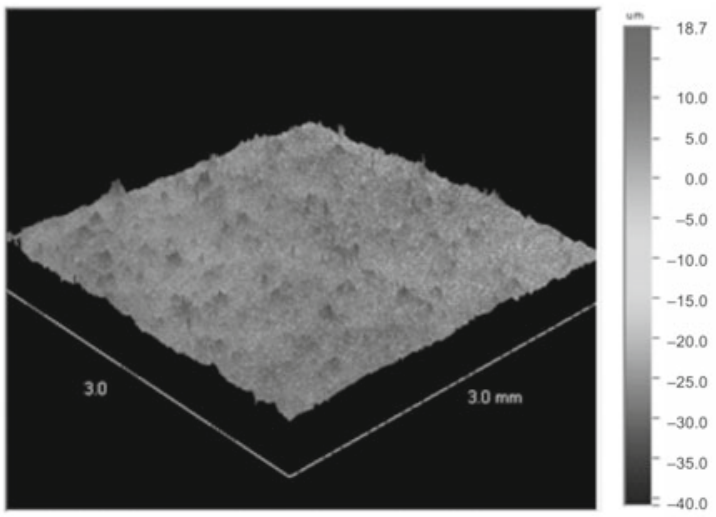

a)

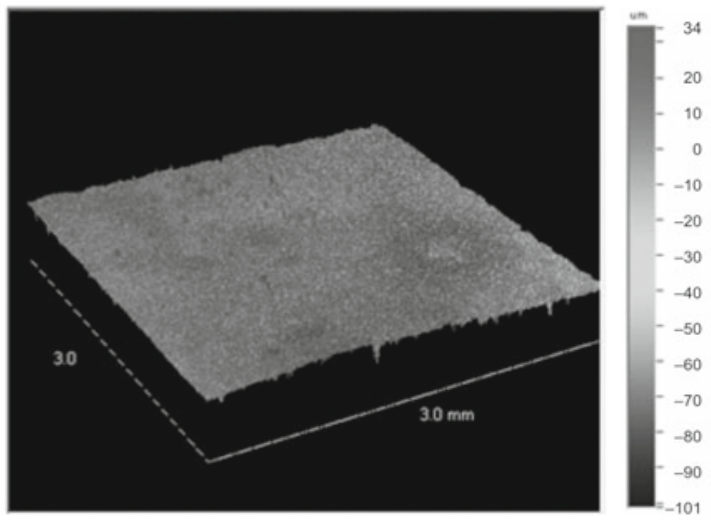

c)
On the basis of the results shown in Figure 7 it can be concluded that the highest adhesion characterizes Al-PTMEG/MDI joint. In this case alumina surface has the lower roughness of all the samples. Better adhesion between PTMEG/MDI and alumina surface is probably due to increased polarity of polyurethane based on MDI than HMDI. When the roughness of alumina surface increases the shear strength of joint based on HMDI is higher than for MDI. It is probably due to the lower viscosity of the prepolymer based on HMDI, as shown in the Figure 8.

With the increase of surface roughness the contact between polyurethane and alumina ceramics decreases. However, prepolymer based on HMDI due to its lower viscosity infiltrates cavities on the ceramic surface more easily. The higher the viscosity of the prepolymer, the more difficulty it filling cavities on the ceramic surface.

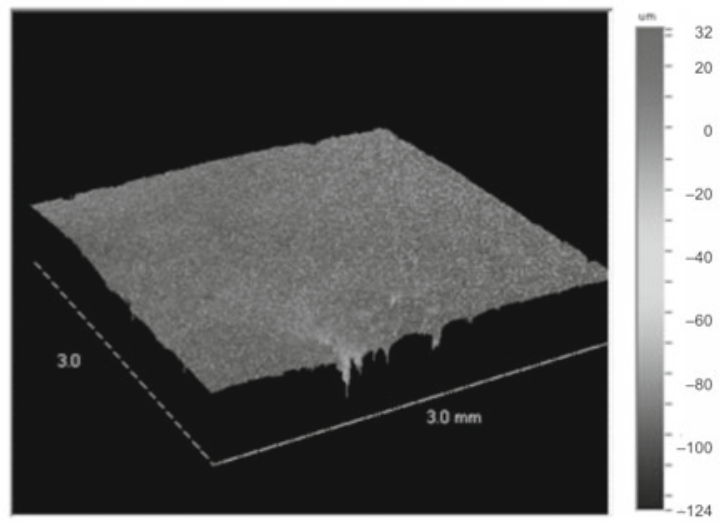

b)

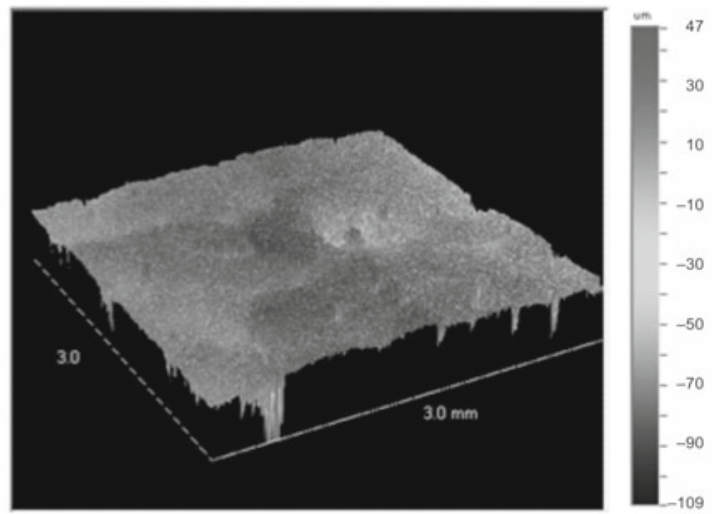

d)

Figure 6. Surface topography of alumina plates (laser profilometer): a) $\mathrm{Al}$, b) $\mathrm{Al} 5 \mathrm{~S}, \mathrm{c}$ ) $\mathrm{Al} 15 \mathrm{~S}, \mathrm{~d}$ ) $\mathrm{Al} 30 \mathrm{~S}$

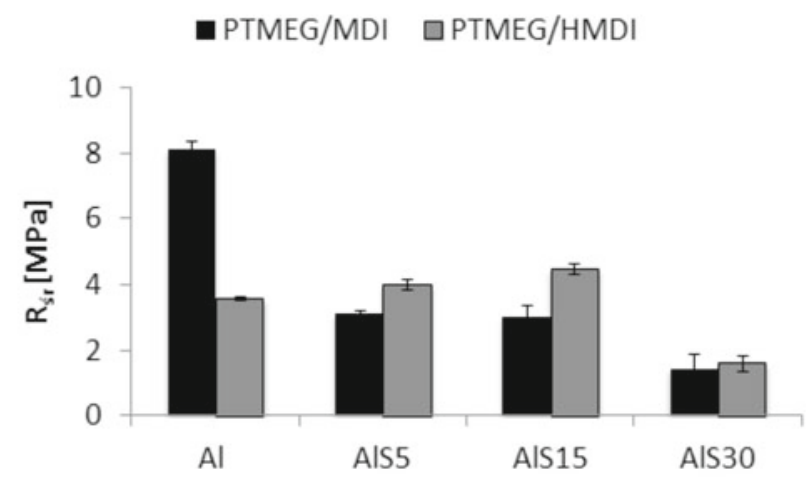

Figure 7. Comparison of shear strength of the polyurethane-alumina joints

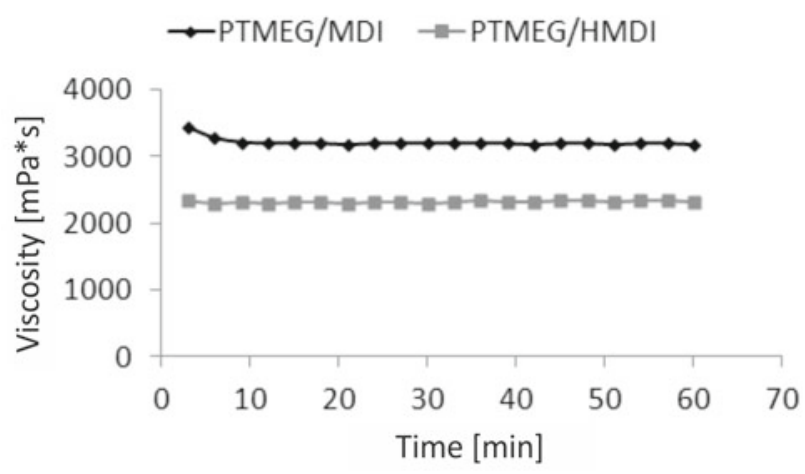

Figure 8. Comparison of the prepolymers viscosity as a function of time 
The best adhesion to alumina ceramics in the case of the PTMEG/HMDI polyurethane was obtained for the sample Al15S.

SEM images of the joints surface after the shear strength test are shown in Figure 9.

Observation of the joints surface microstructure after the shear strength test indicated that in the majority of cases adhesion of PU to the ceramics is poor. Only in the case of Al-PTMEG/MDI joint the failure was cohesive.
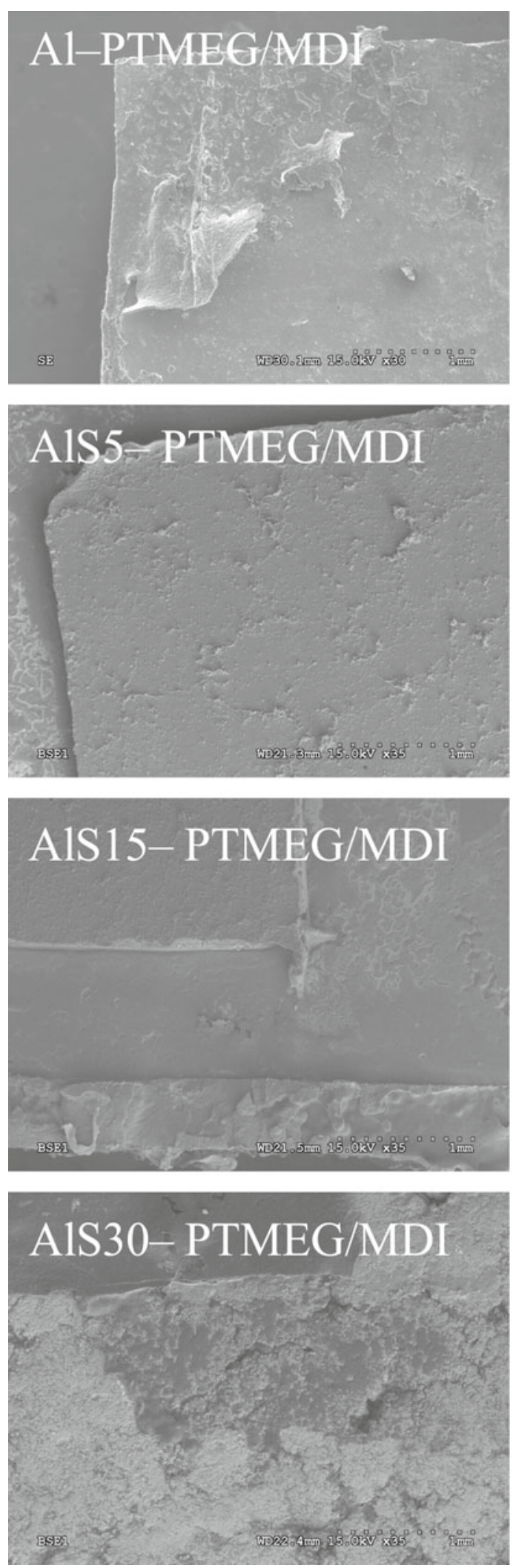

\section{CONCLUSIONS}

This research was the initial part of study on polyurethanes from crystalline prepolymers based on poly(tetramethylene ether) glycol (PTMEG) extended by water for medical application in ceramic-polymer endoprosthesis joint. The commercially available polyurethane with the trade name Pellethane 2363-80A (Dow Chemical) was the reference material in terms of physical and mechanical properties. However, MDI used in Pellethane is undesirable for medical materials, due to toxicity and
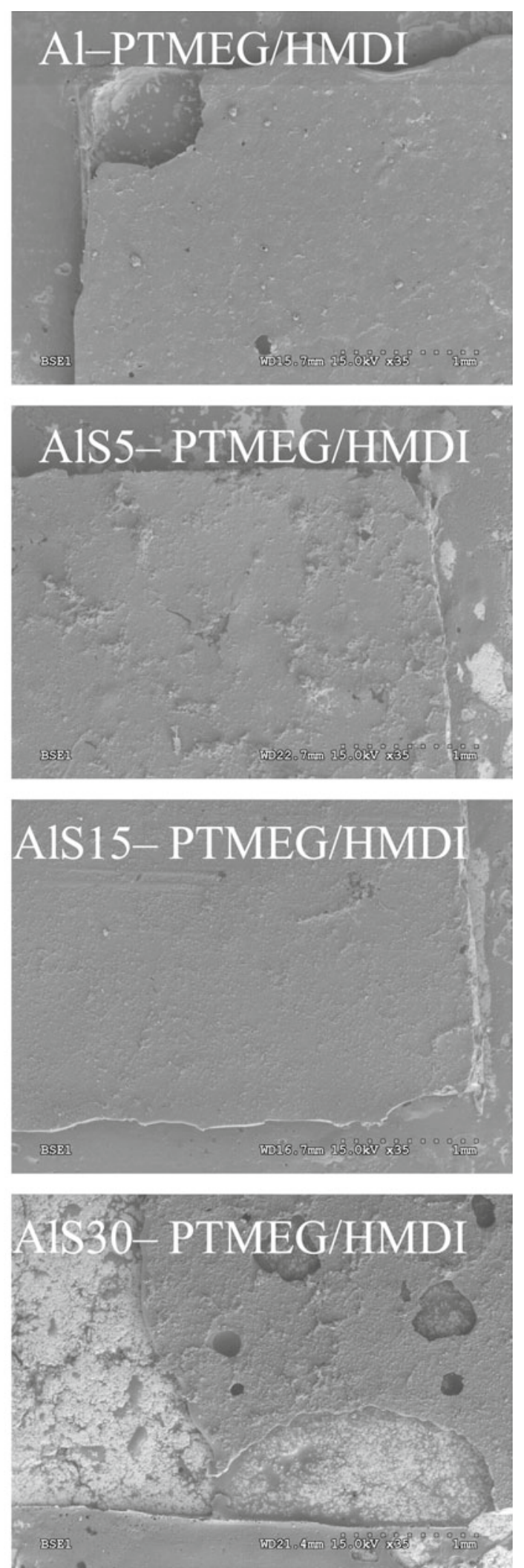

Figure 9. SEM images of the ceramic - polyurethane joints after the shear strength test 
carcinogenicity of its degradation products (aromatic diamines) ${ }^{\mathbf{2 3}, \mathbf{2 4}, \mathbf{2 5}, \mathbf{2 6}}$. Therefore, in the presented studies material that seems to be more useful in medical application was developed. In the course of the research improved properties of hardness, Young's modulus and friction coefficient were obtained for polyurethane based on $4.4^{\prime}$-methylenebis(cyclohexyl)isocyanate (HMDI) in comparison to Pellethane. The results are encouraging in the context of medical application of polyurethanes. Undoubtedly, properties associated with adhesion of polyurethanes to ceramics still require considerable research in order to improve stability of adhesion, of both the polyurethane and the ceramic material surface.

\section{LITERATURE CITED}

1. Nair, L.S., Laurencin, C.T. (2007). Biodegradable polymers as biomaterials Prog. Polym. Sci. 32, 762-798. DOI: 10.1016/j. progpolymsci.2007.05.017.

2. Oledzka, E., Sobczak, M. \& Kołodziej, W.L. (2007). Polymers in medicine - review of past achievements. Polimery 11-12, 793, in Polish.

3. Ryszkowska, J.L., Auguścik, M., Sheikh, A. \& Boccaccini, A.R. (2010). Biodegradable polyurethane composite scaffolds containing Bioglass ${ }^{\circledR}$ for bone tissue engineering. Comp. Sci. Tech. 70, 1894-1908. DOI: 10.1016/j.compscitech.2010.05.011.

4. Waśniewski, B., Auguścik, M., Parzuchowski, P., Zielecka, M. \& Ryszkowska, J. (2012). Polycarbonate urethane nanocomposites with nanosilica for implants of the intervertebral disc. Polimery 11-12, 812, in Polish.

5. Domańska, A., Boczkowska, A., Izydorzak, M., Jaegermann, Z. \& Kurzydłowski, K.J. (2010). Polyurethanes used in the endoprosthesis of joints. Pol. J. Chem. Tech. 12, 3, 10-14. DOI: $10.2478 / \mathrm{v} 10026-010-0025-\mathrm{y}$.

6. Jaegermanna, Z., Boczkowska, A., Paszewska, A. \& Michałowski, S. (2008). Ceramic-polymer gradient composite for joint endoprosthesis application - preliminary report. Pr. Komis. Nauk Ceram. PAN, CERAMIKA, 101, 41-48, in Polish

7. Jaegermann, Z., Boczkowska, A., Domańska, A. \& Michałowski, S. (2008). Composite biomaterial alumina-polyurethane. Pr. Inst. Szkła, Ceramiki, Materiałów Ogniotrwałych i Budowlanych 2, 7-22, in Polish.

8. Gruin, I., Markiewicz, B., Ryszkowska, J., Pacułt, J., Lubaszka, J., Kocjan, R. \& Pasik, J. (1993). "The method of cold cure elastomers fabrication", Know-how no WP/20/93 from 26.03.93 Politechnika Warszawska, in Polish.

9. Boczkowska, A. \& Gruin, I. (1999). Polyurethanes from crystalline prepolymers. Eur. Polym. J. 35, 1569-1579.

10. Boczkowska, A. (2000). Structural polymers obtained from crystalline ether-urethane-isocyanate prepolymers. $\mathrm{PhD}$ thesis, Warszawa, in Polish.

11. Izydorzak, M. (2009). Selection of polyurethanes with increased resistance to abrasive wear for biomedical applications. MSc Thesis - Politechnika Warszawska, Warszawa, in Polish.

12. Wirpsza, Z. (1991). Polyurethanes. Chemistry, technology, applications. Warszawa: WNT, in Polish.

13. Guess, J.F. \& Campbell, J.S. (1995). Acoustic properties of some biocompatible polymers at body temperature. Ultrasound in Medicine \& Biology Vol. 21(2), 273-277.

14. Rudnik, E., Resiak, I. \& Wojciechowski, C. (1998) Thermoanalytical investigations of polyurethanes for medical purposes. Thermochimica Acta 320, 285-289.

15. Martin, D.J., Poole Warren, L.A., Gunatillake, P.A., McCarthy, S.J., Meijs, G.F. \& Schindhelm, K. (2000). Polydimethylsiloxane/polyether-mixed macrodiol-based polyurethane elastomers:biostability. Biomaterials, 1021-1029.

16. Ojha, U., Kulkarni, P., Faust, R. (2009). Syntheses and characterization of novel biostable polyisobutylene based thermoplastic polyurethanes. Polymer 50, 3448-3457.
17. Poussard, L., Burel, F., Couvercelle, J.P., Merhi, Y., Tabrizian, M. \& Bunel, C. (2004). Hemocompatibilty of new ionic polyurethanes: influence of carboxylic group insertion modes. Biomaterials 25, 3473-3483. DOI: 10.1016/j.biomaterials.2003.10.069.

18. Yamamoto, K., Kiura, T., Nam, K., Funamoto, S., Ito, Y., Shiba, K., Katoh, A., Shimizu, S., Kurita, K., Higami, T., Masuzawa, T. \& Kishida, A. (2011). Synthetic polymer-tissue adhesion Rusing an ultrasonic scalpel. Surg. Endosc. 25, 1270-1275. DOI: 10.1007/s00464-010-1357-7.

19. Żenkiewicz, M. (2000). Adhesion and modification of the surface layer of macromolecular materials. Warszawa, WNT, in Polish.

20. Olczyk, W. (1968). Polyurethanes. Warszawa, WNT, in Polish.

21. Rymuza, Z. (1986). Tribology of polymers sliding Warszawa, WNT, in Polish.

22. Schwart, Ch.J. \& Bahadur, S. (2006). Development and testing of a novel joint wear Simulator and investigation of the viability of an elastomeric polyurethane for total-joint arthroplasty devices. Wear 262, 332-339. DOI: 10.1016/j. wear.2006.05.018.

23. Guan, J., Fujimoto, K.L., Sacks, M.S. \& Wagner, W.R. (2005). Preperation and characterization of highly porous, biodegradable polyurethane scaffolds for soft tissue applications. Biomaterials 26, 3961. DOI: 10.1016/j.biomaterials.2004.10.018.

24. Gorna, K. \& Gogolewski, S. (2002). Biodegaradable polyurethanes for implants. II. In vitro degradation and calcification of materials from poly(e-caprolactone)-poly(ethylene oxide) diols and various chain extenders. J. Biomed. Mater. Res., 60(4), 592-606.

25. Guan, J., Sacks, M.S., Beckman, E.J. \& Wagner, W.R. (2002). Synthesis, characterization, and cytocompatibility of elastomeric, biodegradable poly(ester-urethane)ureas based on poly(caprolactone) and putrescine. J. Biomed. Mater. Res. 61(3), 493-503.

26. Gogolewski, S. \& Gorna, K. (2007). Biodegradable polyurethane cancellous bone graft substites in the treatment of iliac crest defects. J. Biomed. Mater. Res. Part A, Volume 80A, Issue 1, 94-101. DOI: 10.1002/jbm.a.30834. 